\title{
INCOME INEQUALITY AMONGST \\ N. Z. WORKERS IN THE 1980s: A \\ DECOMPOSITION ANALYSIS
}

\author{
Barry Martin \\ Population Studies Centre \\ University of Waikato
}

\begin{abstract}
The degree of income inequality within the labour market shrank in the early 1980s and grew in the late 1980s. Three dimensions of interest in income inequality are work status, age and ethnicity. This paper decomposes an index of inequality to ascertain how much of the change in inequality can be attributed to shifts in labour force composition along the three aforementioned dimensions. Through this method we find that change in age and ethnic composition had little effect on aggregate income inequality and that aggregate change between 1981 and 1986 was driven by change within agelethnic and work status groups. Change in work status (i.e. the decline in employment) was a major cuuse of aggregate inequality between 1986 and 1991. Aggregate change between 1986 and 1991 was also due to within-group increases in inequality and divergence of mean incomes among sub-groups.
\end{abstract}

In previous Labour, Employment and Work conferences participants have addressed the changing quantum and type of employment the New Zealand economy has been offering in the 1980s and 1990s, including the experience of the unemployed and part-timers. Other work has documented changes in the rewards of employment over the same period - that is, the distribution of income and earnings (e.g. Easton, 1996; Barker, 1996; Mowbray, 1993). Very little of our work has however addressed causes of change in income and earnings distribution. Some have assumed that there is a connection, while others have either queried the validity of inequality statistics or assumed that any inequality increase is all due to unemployment. In this conference, Sylvia Dixon and I enter this field of enquiry, offering different perspectives. Dixon, building on already-published work (1995 and 1996a) surveys the distribution of earnings of the employed from the mid-1980s up to the present. I offer another perspective, discussing incomes instead of earnings, and incorporating the unemployed and ethnicity into my analysis. I discuss only the 1980 s, starting earlier than Dixon's survey and finishing at 1991 .

Internationally there has been a rise in inequality of earnings and incomes associated largely with economic stagnation post-1974 (Gardiner, 1994; Green, Coder and Ryscavage, 1992). At the heart of the increase in earnings inequality is the secular increase in the demand for skilled workers and a corresponding decrease in demand for less skilled and experienced workers, but the nature of the interaction with the supply side of the labour market - and the role of other crucial factors - in specific countries remains obscure (Gardiner, 1994; Levy and Murnane, 1992).

New Zealand's distribution of income was stable from the
1950 s to the 1970s (Easton, 1983). It then became more unequal in the late 1970 s and again in the late 1980s. In between, in the early 1980 s, there was a period of equalisation of incomes (Martin, forthcoming). As was the case in other OECD countries, the more dramatic shifts in income inequalities from the mid-1970s coincided with a tailing-off of the 'long boom' of the post-War era. In the 1980s, the economy finally underwent a readjustment to the new international economic environment. The readjustment, although tardy, was so radical that it made New Zealand stand out among the developed countries (e. g. Dalziel and Lattimore, 1996, Bagnall, 1996, Wistrich, 1991). The ramifications of the economic reforms were of great public and academic interest, and one of the key questions has been whether such reforms have contributed to or reduced the level of income inequality in New Zealand.

In this paper I discuss relative influence of changes in demographic composition and decline in employment on change in income inequality. The timing of the censuses of 1981,1986 and 1991 roughly captures the last years of the Third National government plus the incoming Fourth Labour government before it began the reform process, then the economic reform period commencing after the 1986 census.

Income distribution can be affected by change in the relative numbers in high-, middle- and low-income categories, and by change in the way different types of income (earnings, dividends, etc.) are distributed. I concentrate only on the former - something which has been termed 'income recipient influences' (Jenkins, 1995), and do not discuss the latter - change in the income itself. By application of a decomposition methodology, I am able to partially answer such questions as how inequality can decrease when unemploy- 
ment is increasing, and how inequality can increase when inequality between defined groups is decreasing. The importance of this closer look at the components of income inequality is that a Gini coefficient or other summary inequality statistic gives insufficient information upon which to base policy. For example, age and ethnic inequalities of income have been increasing since the 1970 s, but this doesn't show up in the 1981-1986 period. The summary statistics for this period indicates only that inequality was decreasing.

\section{Data sources and methodology}

The data used for this paper are of income recipients by age, ethnicity and work status. The source is computerised data files of the 1981, 1986 and 1991 censuses, supplied to the Population Studies Centre by Statistics New Zealand. The census gives annual incomes, and does not distinguish those employed for the whole year from those employed for only part of the year. Given women's propensity to move in and out of remunerated work, the census is a poor source of data on their incomes. For this reason only men's incomes are analysed. The data were grouped using the following categories:

- four age groups ( 15 to 24,25 to 34,35 to 44 and 45 to 59 years),

- four ethnicities (European, Maori, Pacific Islands and Other ethnic groups),

- three work statuses (being employed, unemployed or not actively engaged).

By disaggregating the data using these categories, fortyeight sub-groups were arrived at for each census: $4 \times 4 \times 3=48$.

The aim was to first compute the change in income inequality from census to census, then decompose the change into three elements. These elements were:

(i) change in relative sizes of the sub-groups,

(ii) convergence or divergence of the average incomes of the sub-groups, and the

(iii) inequality within sub-groups.

The methodology used here is described in Mookherjee and Shorrocks (1982), and in Jenkins (1995). This methodology has two sources. One recognises that measured income inequality will change if the relative size of low, middle and high-income groups of the subject population changes. For example, a relative increase in hte number of sole parent households, who tend to have a low income, would contribute to a rise in income inequality among all households. It would therefore be of interest to know how much inequality increase remains (if any) after controlling for change in the relative size of this household sub-group. A methodology tried since the 1970s to control for change in composition is shift-share analysis, a form of standardisation. Research carried out in Britain and the U.S. employing standardisation found that change in demographic composition had made a substantial contribution to an observed increase in income inequality (Danziger and Plotnick, 1977; Semple, 1975). But standardisation has the shortcoming that it oversimplifies actual changes - it only controls for relative sizes of subgroups. The decomposition methodology is an improvement, in that several effects can be distinguished simultane- ously (Mookherjee and Shorrocks, 1982). Thus not only is the effect of change in relativesize of sub-group(s) able to be observed (Terms B and C in formula 5), but also the contribution of change in within-group inequality (Terms A and B) and the effect of movement of sub-groups' average incomes relative to each other (Term D).

The second source is the empirical research in the US in the 1980 s which found that two types of inequality change could be distinguished - change within groups, and change between groups. It was thought that change in income inequality might be due to change in relative size of groups defined by age/experience and education, but it was found that inequality was increasing within such groups, as well as between them (Levy and Murnane, 1992; Dooley and Gottschalk, 1982).

The remainder of this section states the formula for the decomposition, and readers not interested may proceed to the next seciton. In the decomposition formula below, the following notation is used:

$\mathrm{Y}=$ mean income of the aggregate

$y_{g}=$ mean income of the sub-group

$\mathrm{g}=$ sub-group

$\mathrm{i}=$ income interval

$\mathrm{y}_{\mathrm{i}}=$ midpoint of the income interval

$\mathrm{N}=$ number of individuals in the sub-group

$\mathrm{n}_{\mathrm{i}}=$ number of individuals in the income interval

In = natural logarithm

$\Delta=$ intercensal absolute change

$\mathrm{I}=$ index of within-sub-group income inequality

$v=$ sub-group's proportion of total population

$\lambda_{\mathrm{g}}=\mathrm{y}_{\mathrm{g}} / \mathrm{Y}$

$\theta=$ sub-group's proportion of total income

The decomposition is based upon the Mean Logarithmic Deviation, the formula for which in respect of grouped data is:

$$
\sum \frac{n_{i}}{N}\left(\ln \left(\frac{\bar{Y}}{y_{i}}\right)\right)
$$

Most indices of income inequality, including the Mean Logarithmic Deviation (but not the Gini Coefficient), can be applied to data disaggregated into sub-groups,so that the index for aggregate inequality can be decomposed into 'within-group' and 'between-group' components. The decomposition of the Mean Logarithmic Deviation is thus:

$$
\sum_{g}\left(v_{g} I_{g}+\ln \left(\frac{\bar{Y}}{\bar{y}_{g}}\right)\right)
$$

The change in this Mean Logarithmic Deviation between one census (designated time $\mathrm{t}-5$ ) and the next, five years later (designated $\mathrm{t}$ ) is: 


$$
\begin{aligned}
\sum_{g}\left(\left(v_{g} I_{g}\right)_{t}-\right. & \left(v_{g} I_{g}\right)_{t-S}+\left(v_{g} \ln \left(\frac{\bar{Y}}{\bar{y}_{g}}\right)\right)_{t} \\
& \left.-\left(v_{g} \ln \left(\frac{\bar{Y}}{\bar{y}_{g}}\right)\right)_{t-S}\right)
\end{aligned}
$$

We now rearrange the terms in order to decompose change over time into the three effects given above. The reciprocal $-\ln (\lambda)_{t}-\ln (\lambda)_{t-5}$ is substituted for $+\ln \left(Y / y_{g}\right)_{t}-\ln \left(Y / y_{g}\right)_{t-}$ 5 . Change over time is now represented by $\triangle$. Mean values of $\nu, I$ and $\ln (\lambda)$ are used instead of values as at times $(t-5)$ and $(t)$. For further explanation, readers may refer to Mookherjee and Shorrocks (1982), p.896.

$$
\begin{aligned}
& \sum_{g}\left(\bar{v}_{g} \Delta I_{g} \cdot \bar{I}_{g} \Delta v_{g}\right. \\
& \left.-\overline{\ln \left(\lambda_{g}\right)} \Delta v_{g}-\bar{v}_{g} \Delta \ln \left(\lambda_{g}\right)\right)
\end{aligned}
$$

Finally, the absolute mean income $y_{g}$ of the sub-group is substituted in the last term for the relative mean income $\mathrm{y}_{\mathrm{g}}$ $\mathrm{Y}$, and $\left(\theta_{\mathrm{g}}-\lambda_{\mathrm{g}}\right)$ is substituted for $\lambda_{\mathrm{g}}$. This is done to isolate the effect of change of income from change of relative size of sub-group, since $\mathrm{Y}=\mathrm{S}_{\mathrm{g}}\left(v_{\mathrm{g}} \mathrm{y}_{\mathrm{g}}\right)$. Change between censuses in the degree of income inequality is now decomposed as follows:

$\sum_{g}\left(\bar{v}_{g} \Delta I_{g}+\bar{I} \Delta v_{g}+\left(\bar{\lambda}_{g}-\ln \left(\bar{\lambda}_{g}\right)\right) \Delta v_{g}\right.$

$$
\begin{array}{ccc}
\text { Term } A \quad \text { Term } B & \text { Term } C \\
& \left.+\left(\bar{\theta}-\bar{v}_{g}\right) \Delta \ln \left(\bar{y}_{g}\right)\right) \\
& \text { Term } D
\end{array}
$$

Term A represents the influence of change in within-group inequality. The index is weighted by the size of the subgroup over the period in question.

Term B represents the influence of change in population share upon within-group inequality. Here, the relationship of population share to within-group inequality found in Term A is reversed. The shift in population share is weighted by the mean of the indices.

Term $\mathrm{C}$ represents the influence of change in population share upon between-group inequality. The shift in population share is weighted by distance of the group mean income from the mean income of all groups aggregated.

Term D represents the influence of relative changes in subgroup means. The shift in the log of the group mean income is weighted by the disparity between the income share and the population share of the group. Thus the groups with the biggest influence will be those with a large disparity between income share and population share and a large shift in their mean income.

Change in the degree of income inequality in thelabour force can now be decomposed into the four components just described. The following two sections discuss the contribution of change in the relative size of the 48 age/ethnic/work status sub-groups, and change in their income levels relative to each other, to change in aggregate income inequality.

\section{Changes in age and ethnic composition of the labour force}

\section{All Work Statuses}

The results show that income inequality decreased between the censuses of 1981 and 1986, then increased between 1986 and 1991 (Table 1).

Table 1. Change in income inequality among all

\begin{tabular}{llc}
\hline Index & $\begin{array}{c}\text { Per cent change income inequality } \\
1981-86\end{array}$ & $1986-91$ \\
\hline Coefficient of Variation & -5.0 & +3.9 \\
Gini Coefficient & -2.5 & +6.3 \\
\hline
\end{tabular}

The age distribution has a youthful bias, but it is the middle ages (the 30 s and 40s) who were increasing their representation in the labour force in the 1980 s. The 15 to 24 years age group decreased from $28.0 \%$ to $26.5 \%$ of all males between ages 15 and 59 years between 1981 and 1991 , and the 35 to 44 years age group increased from $20.3 \%$ to $23.6 \%$ of all males. At the same time, non-European groups were increasing their share of the total male population, from $14.3 \%$ to $18.8 \%$. Changes in age and ethnic distribution in the 1980 s are shown in Table 2.

Table 2. Age and income distribution of males aged 15 - 59 Years by ethnicity, 1981 to 1991

\begin{tabular}{lrrrr}
\hline Ethnicity & Age & 1981 & 1986 & 1991 \\
\hline A & \multicolumn{5}{c}{ Population Share (\%) } \\
European & $15-34$ & 44.9 & 44.1 & 40.7 \\
Maori and & $35-59$ & 40.8 & 39.7 & 40.5 \\
Pacific Islands & $15-34$ & 8.7 & 9.6 & 10.0 \\
B & $35-59$ & 4.4 & 4.8 & 5.6 \\
European & \multicolumn{5}{c}{ Income Share (\%) } \\
Maori and & $15-34$ & 37.6 & 35.7 & 32.2 \\
Pacific Islands & $35-59$ & 51.9 & 52.0 & 55.1 \\
C & $15-34$ & 5.5 & 6.1 & 5.3 \\
C Income Share - Population Share (\%) & 4.0 & 4.5 & 4.6 \\
European & $15-34$ & -7.3 & -8.4 & -8.5 \\
Maori and & $35-59$ & 11.1 & 12.3 & 14.6 \\
Pacific Islands & $15-34$ & -3.2 & -3.5 & -4.7 \\
\hline
\end{tabular}




\section{Figure 1. Change in income inequality due to four factors 1981-1991}

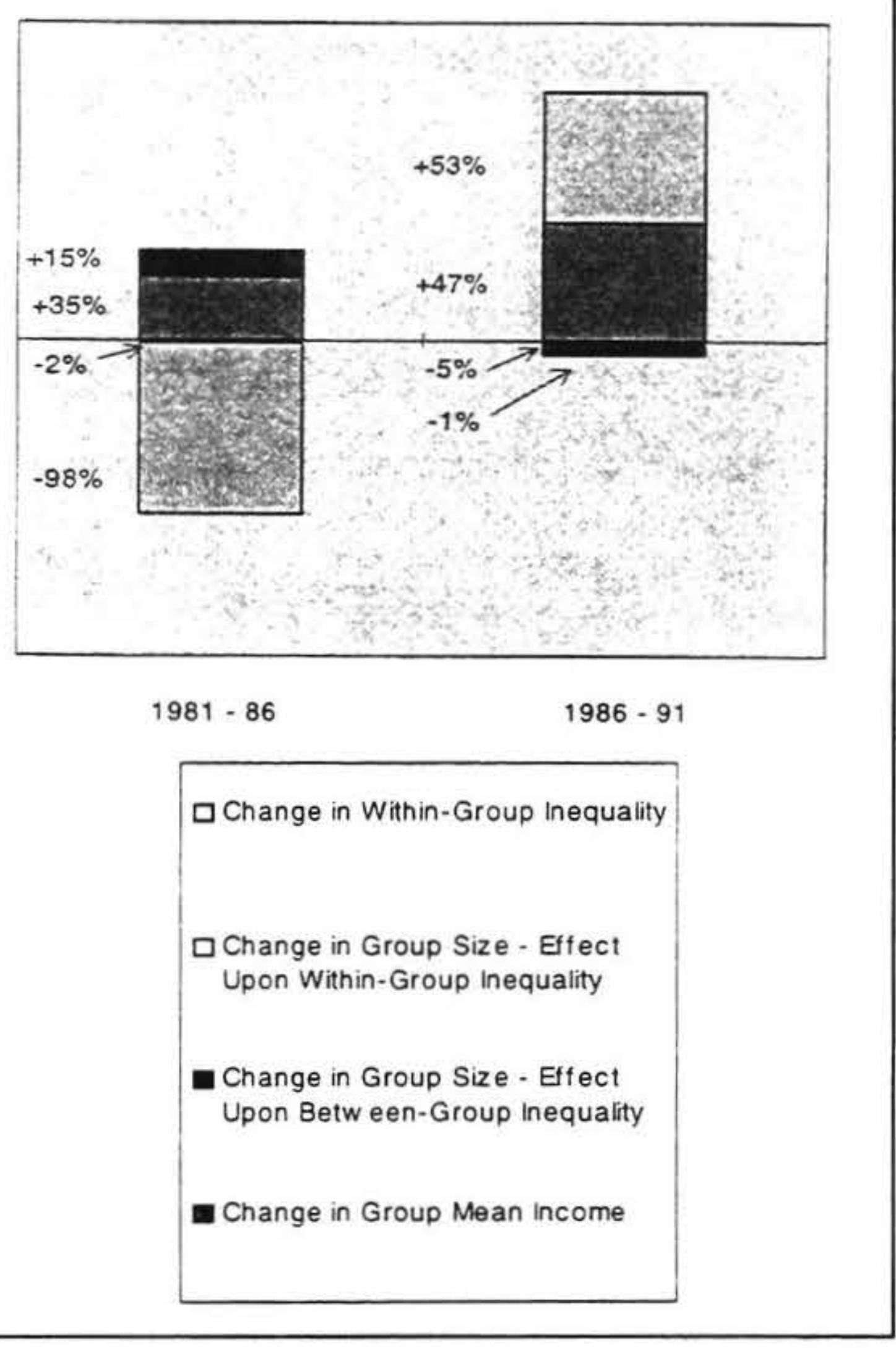

The impact of these shifts in the age and ethnic distribution of the labour force upon measured income inequality may be gauged by grouping individuals by age and ethnicity subgroups only, excluding work status. This will suppress, but not eliminate, the effects of redistribution among work statuses.

Figure 1 shows the change in the inequality index between 1981 - 1986 and 1986 - 1991 decomposed into the four terms described in Section 2. The figure shows that change is due to two factors - movement of mean incomes of the age-ethnic sub-groups between the census years, and the change in degree of inequality within age-ethnic groups.

Through both the early and late 1980 s, average incomes of the age-ethnic sub-groups were diverging, thus increasing inequality. Inequality decreased between 1981 and 1986, because a decrease in inequality within age-ethnic groups outweighed a fall in the incomes of the not actively engaged and unemployed, relative to what they were receiving in 1981. Change in age and ethnic composition was a force increasing income inequality at this time, but its effect was only $15 \%$ of change in inequality in the 1981-1986 period.

The inequality increase between 1986 and 1991 was due to a combination of continued divergence of group mean incomes, and a reversal of the trend in within-group inequality. The age-ethnic redistribution was also a force increasing inequality, but measured only $5 \%$ as a proportion of the other two forces increasing inequality.

The conclusion is therefore that change in composition of income recipients by age and ethnicity is insignificant as an explanation of measured change in income inequality in the 1980s.

\section{The employed}

We now turn to ascertaining the effect of change in age and ethnic composition upon the income distribution of the employed over those two periods. Change in income inequality amongst the employed followed the same pattern observed as when the unemployed and the not actively engaged are included. That is, overall income inequality was decreasing in the early 1980s, and increasing in the late 1980s (Table 3).

Table 3. Change in income inequality for employed males 15-59 Years, 1981 to 1991

\begin{tabular}{lll}
\hline Index & \multicolumn{2}{c}{ Per cent change } \\
& $1981-86$ & $1986-91$ \\
\hline & & \\
Coefficient of Variation & -4.6 & 4.8 \\
Gini Coefficient & -0.6 & 6.3
\end{tabular}

The age and ethnic composition of employed males was changing in a different fashion from that observed amongst all males of employable age, as a comparison of Tables 2 and 4 will show. The proportion of young Maori and Pacific Islanders, although increasing in the total population, was decreasing amongst the employed. By contrast, older Europeans (in spite of keeping a roughly constant proportion of the total population) were forming a larger proportion of the employed.

The net effect of change in age and ethnic distribution amongst employed income recipients in the 1980 s was to decrease measured inequality - the opposite effect of that in the total population. But again, it was a minor influence upon the aggregate change. If we measure the population redistribution effect between 1981 and 1986 as a proportion of the total force decreasing inequality (ie including the compositional shift), then it was only $15 \%$ of the change. Between 1986 and 1991, when inequality was increasing, the compositional shift was a small counter-force, measuring a gain of about $15 \%$ of the the change in inequality.

\section{Changes in work status in the 1980s}

If we combine males of all work statuses as we did for Table 2 , then it can be seen from Panels B and C that older European men have a share of total income considerably larger than their share of the population of males of all work statuses, and that this income share was increasing during the 1980 s. Conversely, the share of income commanded by young Maori and Pacific Island men relative to their population size has shrunk during the 1980s.

This redistribution of aggregate income is largely explained 


\section{Figure 2. Change in income inequality due to four factors 1981-1991}

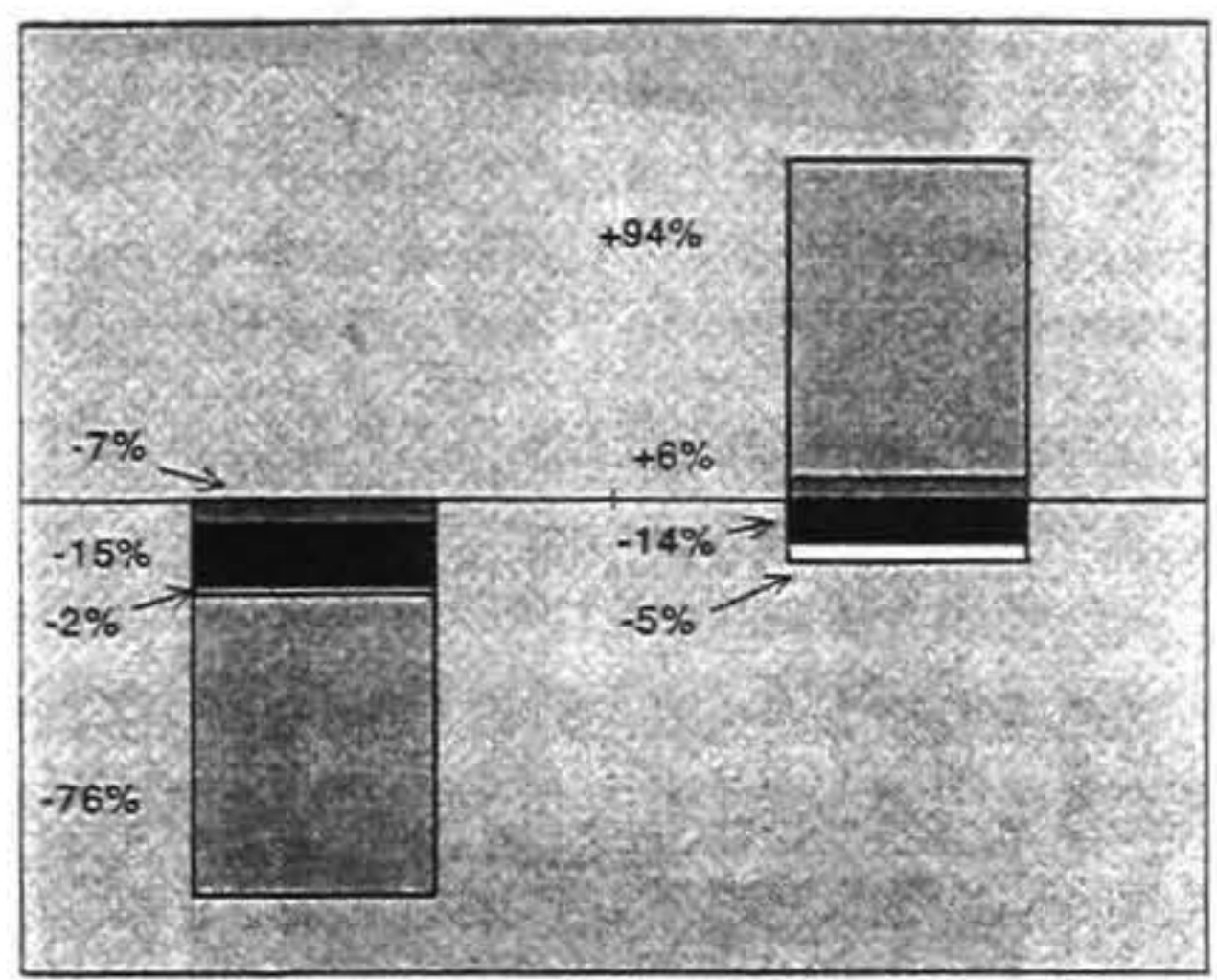

$1981-1986$

$1986-1991$

Change in Within-Group Inequality

- Change in Group Size - Effect Upon Within-Group Inequality

Change in Group Size - Effect Upon Betw een-Group Inequality

Change in Group Mean Income

Table 4. Age and income distribution of males aged between 15 and 59 years by ethnicity, 1981 to 1991

\begin{tabular}{|c|c|c|c|c|}
\hline Ethnicity & Age & 1981 & 1986 & 1991 \\
\hline A & \multicolumn{4}{|c|}{ Population Share (\%) } \\
\hline \multirow[t]{2}{*}{ European } & $15-34$ & 44.3 & 42.0 & 38.7 \\
\hline & $35-59$ & 42.7 & 43.2 & 46.7 \\
\hline Maori \& & $15-34$ & 7.6 & 8.4 & 6.7 \\
\hline Pacific Is. & $35-59$ & 4.3 & 4.9 & 5.0 \\
\hline B & \multicolumn{4}{|c|}{ Income Share (\%) } \\
\hline \multirow[t]{2}{*}{ European } & $15-34$ & 38.3 & 35.5 & 33.2 \\
\hline & $35-59$ & 50.8 & 52.6 & 55.0 \\
\hline Maori \& & $15-34$ & 5.7 & 5.8 & 4.7 \\
\hline Pacific Is. & $35-59$ & 4.0 & 4.4 & 4.4 \\
\hline C & \multicolumn{4}{|c|}{ Income Share - Population Share (\%) } \\
\hline \multirow[t]{2}{*}{ European } & $15-34$ & -6.0 & -6.5 & -5.5 \\
\hline & $35-59$ & 8.2 & 9.4 & 8.2 \\
\hline Maori \& & $15-34$ & -1.9 & -2.5 & -2.0 \\
\hline Pacific Is. & $35-59$ & -0.2 & -0.5 & -0.5 \\
\hline
\end{tabular}

On one hand the above results show a decrease in income inequality amongst males of all work statuses between the 1981 and 1986 censuses, then an increase in the late 1980s. However, according to Table 2, incomes of males of all work statuses was being redistributed in the early 1980s from the young to the old and from Maori and Pacific Islanders to Europeans, suggesting inequality was increasing right through the 1980 s, not just in the second half of the decade.

With respect to the employed, panel $\mathrm{C}$ of Table 4 suggests that inequality between age-ethnic groups was decreasing in the late 1980 s but this contradicts the evidence in Table 3. Figures 2 and 3 show that inequality between groups was indeed changing in the way indicated by the tables, but in each case the between-group effect was outweighed by the changes occurring within groups. Even when taking shifts of individuals beween work statuses into account (Figure 3), a third of the aggregate change can be attributed to those factors changing inequality within the sub-groups.

Clearly then, shifts in income distribution have to be explained in terms of what is going on within work status- and 


\section{Figure 3 Change in income inequality due to four factors, 1981-1991}

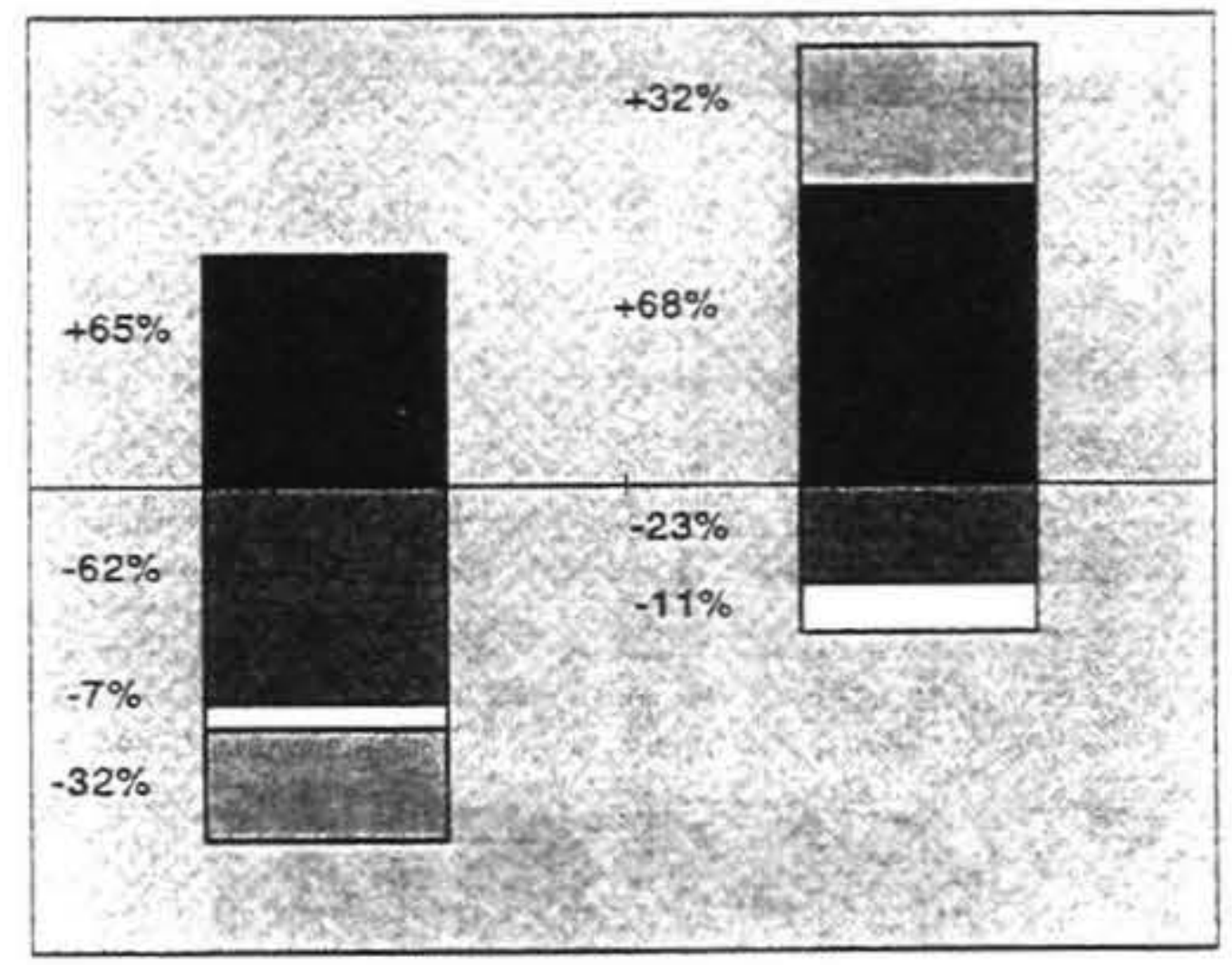

$1981 \cdot 1986$

$1986 \cdot 1991$

$\square$ Change in Within-Group Inequality
$\square$ Change in Group Size - Effect
Upon Within-Group Inequality
Change in Group Size - Effect
Upon Betw een-Group Inequality
Change in Group Mean income

demographically-defined groups. The principal component in income differentials between individuals is earnings, therefore it is necessary to analyse causes of change in earnings differentials. Change in the distribution of earnings is posited to be principally caused by:

(a) change in the age/experience and skills composition of the labour force.

(b) change in the industrial, sectoral and employment status (ie self-employed, wage and salary) composition of employment (Levy and Murnane, 1992).

Behind these 'first order' explanations lies a more abstract 'second order' level of causes:

(c) Labour demand: change in the demand for labour by its quality (highly-skilled relative to less-skilled labour), and by its quantity. Change in demand stems from technological and investment changes.

(d) Labour supply: quantity of the labour force is varied by the rate of entry into the labour force due to fluctuation in size of birth cohorts, rate of entry of women into the labour market, and migration inflows. Quality of the labour force is changed by the rate of growth of higher education and training.

(e) Government incomes policy: the nature and degree of regulation of the labour market. (Levy and Murnane, 1992; Katz and Murphy, 1992; Williamson and Lindert, 1980).

Internationally, understanding of the causes of contempo- rary change in income and earnings inequality has not grown commensurately with its growth as a public policy concern. Economic theory has been helpful in certain respects, such as understanding the determination of wages and salaries, but a comprehensive theoretical framework integrating all aspects of income is still lacking. (Atkinson, 1994).

Similarly, while empirical research has increased our understanding, it leaves many gaps. The United States has the most advanced and comprehensive research and therefore a brief summary will be useful. The focus of U. S. research has been on the role of cohort sizes, age or experience, and education. It has been found that the premium for education/ skills declined in the 1970s, due to the arrival of collegeeducated baby-boomers on the labour market. At the same time, the baby-boomers caused an increase in the premium for age/experience, as older workers shrank as a proportion of the total labour force. In the 1980s, because of a fall-off in the rate of entry into higher education, the education/skills premium increased dramatically. These changes can be summarised in table form (Table 6). American research has however only been able to explain part of the observed increase in earnings inequality. The effect of shifts in demand for certain types of worker within industries, and the role of political changes to the wage and salary setting environment is not yet known (Levy and Murnane, 1992).

The foregoing suggests then, that research on income and earnings in New Zealand should proceed along three lines:

(a) an analysis of the relationship between the structure of employment and change in earnings.

(b) the size, age, experience and educational composition of the labour force and earnings trends, and

(c) between change in the institutional structure of pay fixing and change in earnings inequalities.

\section{Summary}

Income inequality decreased between the 1981 and 1986 censuses, then increased strongly between 1986 and 1991 . This was the case even when the unemployed and not actively engaged were excluded. As at 1991, incomes were more unequal than they had been in the entire post-War era. Measured by the Gini coefficient, the increase in inequality in the five years between 1986 and 1991 (6.3 percentage points) was of a greater magnitude than the slight decline in the twenty five years between 1951 and 1976 (2.1 percentage points)(Martin, forthcoming).

Change in age and ethnic composition of income recipients has been a very minor cause of this change in income inequality in the male labour force in the 1980s. Its exact effects depend on which work status group is being considered. For the employed, it was a force decreasing inequality. In the 1980s, younger (low-income) Maori and Pacific Islanders formed a decreasing percentage of the employed, even though they were forming an increasing proportion in society. Conversely, older (high-income) Europeans, who have been a shrinking number in relative terms in society as a whole, came to form a higher proportion of the employed by 1991 . Aggregating all males of employable age (15 to 59 

differentiation by age/experience and education/skill

\begin{tabular}{|c|c|c|c|c|}
\hline Decade & $\begin{array}{l}\text { Between Education/ } \\
\text { Skill Groups }\end{array}$ & $\begin{array}{l}\text { Between Age/Exp } \\
\text {-erience Groups }\end{array}$ & $\begin{array}{l}\text { Within Skill/Exp } \\
\text {-erience Groups }\end{array}$ & $\begin{array}{l}\text { Total } \\
\text { Inequality }\end{array}$ \\
\hline $\begin{array}{l}1970 \text { s } \\
1980 \text { s }\end{array}$ & $\begin{array}{l}\text { Declining } \\
\text { Increasing }\end{array}$ & $\begin{array}{l}\text { Increasing } \\
\text { Declining }\end{array}$ & $\begin{array}{l}\text { Declining } \\
\text { Increasing }\end{array}$ & $\begin{array}{l}\text { Stable }^{1} \\
\text { Increasing }\end{array}$ \\
\hline
\end{tabular}

1. Or a slight increase, depending on the dataset/researcher.

2. The premium for age/experience was increasing for workers with a secondary education but decreasing for workers with a university education.

Source: Levy and Murnane 1992; Katz and Murphy, 1992

years) irrespective of whether they were employed, unemployed or not actively engaged, we find that the increase in the proportion of individuals in their thirties and an increase in the proportion of non-Europeans was contributed to the increase in inequality.

The intuition that a decrease in the proportion of males employed would be a major cause of an increase in income inequality is supported by our analysis. Overall inequality decreased in the early 1980s because the effect of declining employment was negated by a large decrease in inequality amongst the employed. In the late 1980s, however, inequality increased amongst the employed thus adding to the effect of rising unemployment. The rise in inequality in the late 1980s was two-thirds due to the decline in employment and one-third to the increase in inequality amongst the employed.

The decline of employment is clearly a major explanation of changes in income inequality in the 1980 s, yet much more remains to be explained. Apart from the increase in inequality in the late 1980 s, there is evidence that inequality was already increasing amongst the employed in the late 1970s. We thus have two episodes of increasing inequality, in between which there was one of decreasing inequality. Do these have the same cause or combination of causes? What is the role of deregulation of the labour market in increasing earnings inequality? How has the changing industrial and sectoral structure of the economy affected earnings inequality? What has been the effect of demographic and educational changes to the labour force? These are questions of general public interest, and also of practical public policy application, which our research should address.

\section{References}

Atkinson, A. B. (1994). Seeking to Explain the Distribution of Income. Welfare State Programme Discussion Paper 106. London: Suntory-Toyota International Centre for Economics and Related Disciplines (STICERD), London School of Economics.

Bagnall, D. 1996 Still room for recovery" Bulletin October 15 1996: 30-33.

Barker, G. 1996 Income distribution in N. Z. Wellington: Institute of Policy Studies.
Dalziel, P. and Lattimore, R. 1996 The New Zealand Macroeconomy: A briefing on the reforms. Auckland: Oxford University Press.

Danziger, S. and Plotnick, R. 1977 Demographic change, government transfers, and income distribution Monthly Labor Review April 1977.

Dixon, S. 1995 The Inter-Industry Wage Structure: 19711994 Labour Market Bulletin 199(1): 45-100.

Dooley, M. and Gottschalk, P. 1982 "Does a younger male labor force mean a greater earnings inequality? Monthly Labor Review 105(11):42-45.

Easton, B. H. 1983 Income Distribution in New Zealand. New Zealand Institute of Economic Research Research Paper no. 28 Wellington: NZIER.

Easton, B. H. 1996 Income Distribution in B. Silverstone, A. Bollard, and R. Lattimore: A Study of Economic Reform: the Case of New Zealand Amsterdam: North Holland. Pp. 100-138

Gardiner, K. 1993 A survey of income inequality over the last twenty years - how does the UK compare? Welfare State Programme Discussion Paper 100. London: Suntory- Toyota International Centre for Economics and Related Disciplines (STICERD), London School of Economics.

Green, G., Coder, J. and Ryscavage, P. 1992 International comparisons of earnings inequality for men in the 1980s Review of Income and Wealth 18(1): 1-15.

Jenkins, S. P. 1995 Accounting for inequality trends: decomposition analyses for the UK, 1971-86. Economica 62(245): 29-63.

Katz, L. F. and Murphy, K. M. 1992 Changes in Relative Wages, 1963 - 1987: Supply and Demand Factors Quarterly Journal of Economics 107(1): 35-78.

Levy, F. and Murnane, R. J. 1992 U.S. Earnings Levels and Earnings Inequality: A Review of Recent Trends and Proposed Explanations. Journal of Economic Literature 30(2):1333-1381. 
Martin, B. J. (forthcoming) Away from equality: change in personal incomes 1951 to 1991 Population Studies Centre Discussion Paper Series.University of Waikato.

Mowbray, M. 1993 Incomes Monitoring Report, 19811991 Social Policy Agency, Wellington.

Mookherjee, D. and Shorrocks, A. 1982 A decomposition analysis of the trend in UK income inequality Economic Journal 92(Dec):886-902.

Semple, M. 1975 The effect of changes in household composition on the distribution of income Economic Trends 266:99-105.

Williamson, J. G., and Lindert, P. H. 1980 American inequality: a macroeconomic history New York: Academic Press.

Wistrich, E. 1991 The Fourth Labour Government British Review of New Zealand Studies 4:11-18.

\section{Author}

Barry Martin is a Doctoral candidate at the Population Studies Centre, University of Waikato. 